\title{
不同熟期玉米不同粒位籽粒灌浆和脱水特性对密度的响应
}

\author{
朱亚利 ${ }^{1}$ 王晨光 $^{2}$ 杨 梅 $^{1}$ 郑学慧 ${ }^{1}$ 赵成风 ${ }^{1}$ 张仁和 ${ }^{1, *}$
}

${ }^{1}$ 西北农林科技大学农学院, 陕西杨凌 $712100 ;{ }^{2}$ 陕西省农业技术推广总站, 陕西西安 710003

摘 要: 研究密度对不同熟期玉米品种不同粒位的籽粒灌浆和脱水特性的调控效应, 为陕北灌区春玉米密植高产机 械粒收技术提供依据。于 2018-2019 年以中熟品种先玉 335 (Xianyu 335)和晚熟品种东单 60 (Dongdan 60)为材料, 设 置 45,000 (D1)、60,000 (D2)、75,000 (D3)、90,000 (D4)株 $\mathrm{hm}^{-2}$ 四个种植密度, 分析其不同粒位籽粒灌浆、脱水特性 及其与气候因子的相关性。结果表明, 密度的增加能显著提高不同熟期品种玉米籽粒产量, 其中 2018 年 2 个品种均 在 D4 处理下达到最高产量; 2019 年先玉 335 和东单 60 分别在 D4 和 D3 处理下达到最高产量, 2 年平均最高产量分 别为 $18,739 \mathrm{~kg} \mathrm{hm}^{-2}$ 和 $17,111 \mathrm{~kg} \mathrm{hm}^{-2}$, 较 D1 处理产量分别提高了 $32.2 \%$ 和 $27.7 \%$ 。随着种植密度的增加, 不同粒位 的籽粒灌浆速率降低, 粒重减小, 脱水速率加快。在 D4 种植密度下, 先玉 335 下部和上部籽粒平均灌浆速率较东单 60 分别高 $0.08 \mathrm{~g} \mathrm{~d}^{-1}$ 和 $0.04 \mathrm{~g} \mathrm{~d}^{-1}$, 粒重较东单 60 分别高 $3.6 \mathrm{~g}$ 和 $1.6 \mathrm{~g}$ 。生理成熟时不同粒位的籽粒含水率与吐丝到 生理成熟间有效积温呈显著正相关, 总脱水速率与灌浆速率相关性不显著。先玉 335 不同粒位的籽粒脱水速率快, 且 下部和上部籽粒平均脱水速率较东单 60 高 0.006 和 $0.005 \%{ }^{\circ} \mathrm{C} \mathrm{d}^{-1}$ 。与下部籽粒比, 上部籽粒灌浆速率低、灌浆期长、 粒重小、后期脱水快、含水率达到 28\%和 $25 \%$ 所需积温少。可见, 2 个品种籽粒灌浆和脱水特性对增密的响应其上部 籽粒更敏感; 与东单 60 相比, 先玉 335 密植下籽粒灌浆速率高, 粒重大, 且后期脱水速率快。因此, 选择中熟品种结 合适宜增密能够实现陕北灌区玉米密植高产机械粒收生产。

关键词: 春玉米; 熟期; 粒位; 籽粒灌浆; 脱水特性; 产量

\section{Response of grain filling and dehydration characteristics of kernels located in different ear positions in the different maturity maize hybrids to plant density}

\author{
ZHU Ya-Li ${ }^{1}$, WANG Chen-Guang ${ }^{2}$, YANG Mei ${ }^{1}$, ZHENG Xue-Hui ${ }^{1}$, ZHAO Cheng-Feng ${ }^{1}$, and ZHANG \\ Ren-He ${ }^{1, *}$ \\ ${ }^{1}$ College of Agronomy, Northwest A\&F University, Yangling 712100, Shaanxi, China; ${ }^{2}$ Shaanxi Agronomy and Technology Extension Station, Xi'an \\ 710003, Shaanxi, China
}

\begin{abstract}
Exploring the regulation effect of planting density on grain filling and dehydration characteristics of kernels located in different ear positions in different maturity maize hybrids could provide theoretical and technical reference for high yield production for the mechanized grain harvest of spring maize in northern Shaanxi irrigation area. A field experiment was conducted using the medium maturity maize hybrid Xianyu 335 and the late maturity maize hybrid Dongdan 60 with four plant densities of 45,000 (D1), 60,000 (D2), 75,000 (D3), and 90,000 (D4) plants $\mathrm{hm}^{-2}$ from 2018 to 2019. Their grain filling and dehydration characteristics at different grain positions and their correlation with climatic factors were analyzed. The results showed that increasing density could significantly increase the grain yield with different maturity maize hybrids with both hybrids reaching the highest yield under D4 treatment in 2018; Xianyu 335 and Dongdan 60 reached the highest yield under D4 and D3 treatments in 2019, respectively, and the 2-year average highest yields were $18,739 \mathrm{~kg} \mathrm{hm}^{-2}$ and $17,111 \mathrm{~kg} \mathrm{hm}^{-2}$, which were $32.2 \%$ and $27.7 \%$ higher than
\end{abstract}

本研究由国家重点研发计划项目 (2017YFD0300304), 陕西省重点研发计划项目 (2017ZDCXL-NY-02-02)和陕西省技术创新引导专项 (2019TG-002)资助。

This study was supported by the National Key Research and Development Program of China (2017YFD0300304), the Shaanxi Key Research and Development Program (2017ZDCXL-NY-02-02), and the Shaanxi Technology Innovation and Guide Project (2019TG-002).

"通信作者(Corresponding author): 张仁和, E-mail: zhangrenhe1975@163.com

第一作者联系方式: E-mail: zhuyali1994@126.com

Received (收稿日期): 2020-05-06; Accepted (接受日期): 2020-10-14; Published online (网络出版日期): 2020-10-28.

URL: https://kns.cnki.net/kcms/detail/11.1809.S.20201028.1209.002.html 
those under D1 treatment. With the increase of plant density the grain filling rate and the grain weight decreased, and the dehydration rate accelerated of different grain positions. Under D4 plant density, the average grain filling rate of the lower and upper grains of Xianyu 335 was $0.08 \mathrm{~g} \mathrm{~d}^{-1}$ and $0.04 \mathrm{~g} \mathrm{~d}^{-1}$ higher than that of Dongdan 60 , and the grain weight was $3.6 \mathrm{~g}$ and $1.6 \mathrm{~g}$ higher than that of Dongdan 60, respectively. The correlation analysis showed that the grain moisture content of different grain positions was positively correlated with the effective accumulated temperature from silking to physiological maturity stage, but the total dehydration rate was not significantly correlated with grain filling rate. The grain dehydration rate of Xianyu 335 at different grain positions was high, and the average total dehydration rate of lower and upper grains was $0.006 \%{ }^{\circ} \mathrm{C} \mathrm{d}{ }^{-1}$ and $0.005 \%$ ${ }^{\circ} \mathrm{C} \mathrm{d}^{-1}$ higher than that of Dongdan 60. Furthermore, compared with the lower grains, the upper kernels had lower filling rate, longer filling period, smaller grain weight, faster dehydration at the later stage, and required less accumulated temperature to reach $28 \%$ and $25 \%$ moisture content. Based on our study, the upper kernels were more sensitive to higher plant density than lower kernels. Compared with Dongdan 60, the mid-mature maize hybrid Xianyu 335 has the higher grain filling rate, larger grain weight, and faster dehydration rate in the dense planting conditions. In conclusion, properly increased plant density coupled with middle-maturity maize hybrids is a potential way to increase the grain yield for mechanized grain harvest in the irrigation area of Northern Shaanxi.

Keywords: spring maize; hybrid maturity; grain position; grain filling; dehydration characteristics; grain yield

玉米是世界也是我国第一大粮食作物，为保障 国家粮食安全起到重要的作用 ${ }^{[1]}$ 。增加种植密度是 玉米增产的主要措施之一 ${ }^{[2-3]}$; 但高密度种植会加剧 植株间光照和养分的竞争, 导致单株穗粒数和粒重 减少, 最终减产 ${ }^{[4]}$ 。玉米产量构成中若穗粒数确定后, 粒重成为决定籽粒产量的重要因子 ${ }^{[5]}$; 且粒重的形 成存在粒位效应 ${ }^{[6]}$ 。研究发现, 授粉后雌穗杼粒的 发育表现为中下部籽粒较好, 上部籽粒发育最差, 这种效应在低氮、干旱等非生物逆境下表现更为明 显 ${ }^{[7-9]}$ 。而增密对不同粒位籽粒粒重的影响也值得深 入研究, 这对集约化种植下进一步提高玉米产量具 有现实意义。

随着玉米生产方式的改变, 机械化粒收已成为 玉米生产的必然趋势, 降低收获时籽粒含水率是实 现玉米机械化粒收的重要保障 ${ }^{[10-11]}$ 。收获时䊏粒含 水率的变化由籽粒灌浆和籽粒脱水 2 个关键因素分 阶段主导, 且与籽粒灌浆速率和植株的衰老密切相 关 ${ }^{[12-13]}$ 。选择不同熟期品种是影响玉米籽粒产量、 含水率和密度关系的重要因素 ${ }^{[14]}$ 。研究表明, 榆林 地区光温资源较为丰富, 早熟品种籽粒从授粉到开 始脱水所需积温少, 后期脱水快, 但较中熟和晚熟 品种产量优势不明显 ${ }^{[15]}$; 而晚熟品种易导致籽粒收 获时成熟度不足, 含水量高的问题 ${ }^{[16]}$ 。在一定范围 内, 随着种植密度的增加, 玉米籽粒灌浆活跃时期 延长, 灌浆速率减小, 收获时含水率下降 ${ }^{[17]}$ 。由此看 来, 协调好品种熟期、籽粒灌浆、脱水特性及密度 配置关系, 对实现密植高产机械化粒收生产具有重 要意义。目前, 关于玉米不同粒位的籽粒灌浆研究 多见于温度胁迫和播期等方面 ${ }^{[18-19]}$; 而不同熟期品 种和密度配置对玉米不同粒位的籽粒灌浆、脱水特
性及产量的影响研究鲜见报道。为此, 本研究通过 密度调控对不同熟期品种玉米不同粒位的籽粒灌浆 和脱水特性进行探讨, 以期为陕北灌区春玉米密植 高产机械化粒收技术提供支撑。

\section{1 材料与方法}

\section{1 试验地概况与试验设计}

试验于 2018-2019 年在陕西省榆林市西北农 林科技大学玉米试验示范站 $\left(109^{\circ} 45^{\prime} \mathrm{N}, 38^{\circ} 16^{\prime} \mathrm{E}\right)$ 进 行。土壤类型为沙壤土, $0 \sim 20 \mathrm{~cm}$ 耕层土壤含有机质 $6.76 \mathrm{mg} \mathrm{kg}^{-1}$ 、速效氮 $42.75 \mathrm{mg} \mathrm{kg}^{-1}$ 、速效磷 16.98 $\mathrm{mg} \mathrm{kg}^{-1}$ 、速效钾 $99.77 \mathrm{mg} \mathrm{kg}^{-1}$ 。试验期间具体温度 和降雨量详见图 1。2018 年和 2019 年播种日期分 别为 4 月 30 日和 4 月 29 日，收获日期均为 10 月 1 日。选用 2 个生产上大面积应用的玉米品种先玉 335 (中熟品种)和东单 60 (晚熟品种)为试验材料, 设置 45,000、60,000、75,000 和 90,000 株 $\mathrm{hm}^{-2}$ 四 个种植密度, 小区行长 $6 \mathrm{~m}$, 宽 $3 \mathrm{~m}$, 小区面积 $18 \mathrm{~m}^{2}$ 。 等行距种植, 行间距 $0.6 \mathrm{~m}$, 每个小区内种植 5 行, 4 次重复。肥料用量为纯氮 $240 \mathrm{~kg} \mathrm{hm}^{-2} 、 \mathrm{P}_{2} \mathrm{O}_{5} 90 \mathrm{~kg}$ $\mathrm{hm}^{-2}$ 和 $\mathrm{K}_{2} \mathrm{O} 120 \mathrm{~kg} \mathrm{hm}^{-2}$, 氮肥为尿素(含纯氮 $46 \%$ ), 磷肥为过磷酸钙 (含 $\mathrm{P}_{2} \mathrm{O}_{5} \quad 17 \%$ ), 钾肥为氯化钾 (含 $\left.\mathrm{K}_{2} \mathrm{O} 60 \%\right)$ 。氮肥分别于播种时施入 $40 \%$ ，小喇叭口 期施入 $60 \%$ ，磷钾肥全部基肥施入，其他田间管理 同大田生产。

\section{2 测定项目方法}

1.2.1 生育进程调查与积温计算播种后及时观 察并记录各处理吐丝期(R1)及生理成熟期(R6)的时 间, 生理成熟以果穗中下部籽粒黑层出现, 乳线消 失日期为准。气象数据由陕西省榆林市西北农林 

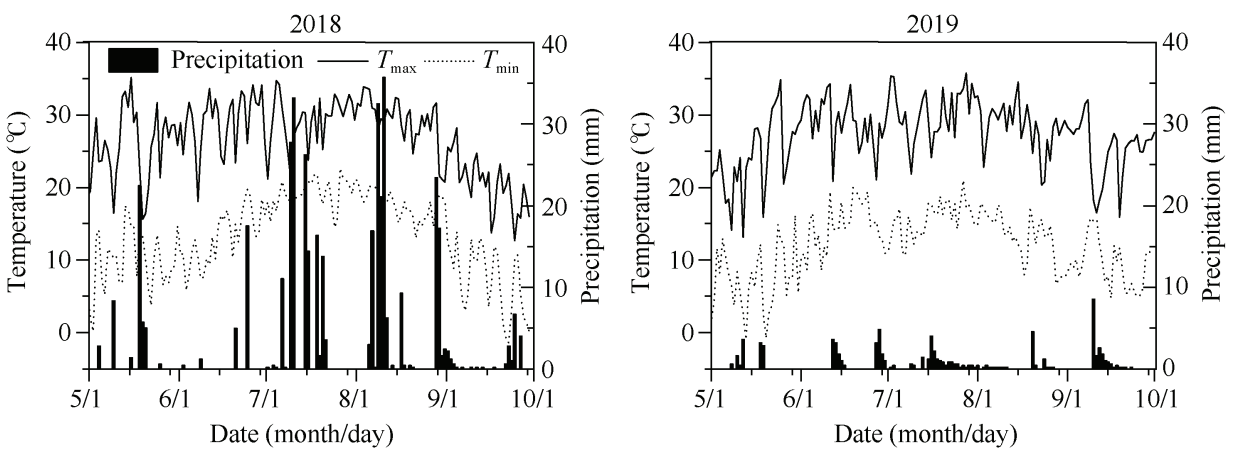

图 $12018-2019$ 年玉米生育期气温和日降雨变化

Fig. 1 Temperature and daily rainfall changes during the growth period of maize in 2018 and 2019

科技大学玉米试验示范站提供, 参照严定春等方法 计算有效积温 ${ }^{[20]}$ 。第 $i$ 天的累积有效积温 $T$ $=\sum_{i=1}^{i}\left[\left(T_{\max }+T_{\min }\right) / 2-10\right]$, 其中, $T_{\max }$ 和 $T_{\min }$ 为第 $i$ 天的最高和最低气温。

\subsection{2 籽粒灌浆和脱水特性 于吐丝期在小区内} 选取长势均匀的植株自吐丝后 $7 \mathrm{~d}$ 开始, 而后每隔 7 $\mathrm{d}$ 从标记植株中随机选取 3 个均匀果穗, 然后用尺子 测量其长度, 并用刀子从中间部位切开分为上下 2 部分，从上下 2 部分籽粒中选取长势均匀的 2 行, 记 录籽粒数目并称重, 然后在 $105^{\circ} \mathrm{C}$ 下杀青 $30 \mathrm{~min}$, $80^{\circ} \mathrm{C}$ 烘干至恒重, 称重并记录。

籽粒灌浆速率 $\left(\mathrm{g} \mathrm{d}^{-1}\right)=[$ 本次测定的百粒干重 $(\mathrm{g})-$ 前一次测定的百粒干重 $(\mathrm{g})] / 2$ 次测定的间隔日数 (d)

籽粒含水率 $(\%)=(1-$ 籽粒干重/籽粒鲜 重) $\times 100 \%$

籽粒脱水速率 $\left(\%{ }^{\circ} \mathrm{C} \mathrm{d}^{-1}\right)=$ 生理成熟时籽粒含 水率/吐丝后有效积温

籽粒灌浆参数通过 Logistic 方程模拟计算 ${ }^{[21]}$, 模型形式如下:

$$
W=a /[1+b \times \exp (-c t)]
$$

式中, $W(\mathrm{~g})$ 表示测定的籽粒百粒干重 $(\mathrm{g}), t(\mathrm{~d})$ 为自变量, 即吐丝后天数, $a 、 b 、 c$ 和 $d$ 是拟合的灌浆特征参数, 利 用以下公式计算灌浆参数 ${ }^{[21]}$ 。籽粒灌浆速率达到最大时 所需的天数 $\left(T_{\max }, \mathrm{d}\right): T_{\text {max }}=\ln b / c$; 籽粒灌浆速率达到最 大时籽粒的干重 $\left(W_{\max }, \mathrm{g}\right): W_{\text {max }}=a /\left[1+b \times \exp \left(-c \times T_{\max }\right)\right]$; 籽粒的最大灌浆速率 $\left(G_{\max }, \mathrm{g}\right.$ kernel $\left.^{-1} \mathrm{~d}^{-1}\right): G_{\max }=$ $a \times b \times c \times \exp \left(-c \times T_{\max }\right) /\left[1+b \times \exp \left(-c \times T_{\max }\right)\right]^{2}$; 籽粒平均 灌浆速率 $\left(G_{\text {mean }}, \mathrm{g} \mathrm{kernel}^{-1} \mathrm{~d}^{-1}\right): G_{\text {mean }}=a c / 6$; 籽粒活 跃灌浆持续时间 $(D, \mathrm{~d}): D=a / G_{\text {mean。 }}$ 。

籽粒含水率模型采用 Logistic power 非线性增 长模型建立回归模型 ${ }^{[22]}$, 模型形式如下:

$$
\mathrm{MC}=a /(1+T / b)^{c}
$$

式中, $a 、 b 、 c$ 为模型参数, $T\left({ }^{\circ} \mathrm{C} \mathrm{d}\right)$ 为自变量, 即授 粉后有效积温, $\mathrm{MC}(\%)$ 为因变量, 即籽粒含水率。

1.2.3 产量及其构成因素在成熟期, 统计小区 倒伏率和空秆率，每个小区收获靠近中间位置且长 势均匀的 3 行进行记产, 根据小区平均产量, 选取 10 个果穗调查穗长、秃尖长、穗粗、穗行数和行粒 数等穗部性状, 记产时籽粒含水率统一折算成 $14 \%$ 。

\section{3 数据统计与分析}

采用 Microsoft Excel 2019 进行数据整理, SPSS 12.0 软件统计和分析数据, Origin 2017 进行绘图, Curve Expert 2.6 进行曲线拟合。

\section{2 结果与分析}

\section{1 密度对不同熟期玉米产量及产量构成的} 影响

随着种植密度的增加，不同熟期品种产量显著 提高(表 1)。方差分析表明, 不同熟期品种玉米的穗 粒数和百粒重随着种植密度的增加显著下降, 而有 效穗数显著增加 $(P<0.05) 。 2$ 年的产量表现一致, 先 玉 335 平均产量较东单 60 高 $8.9 \%\left(1303 \mathrm{~kg} \mathrm{hm}^{-2}\right)$; 2018 年 2 品种均在 D4 种植密度下达到最高产量; 2019 年分别在 D4 (先玉 335) 和 D3 (东单 60)达到最 高产量, 2 年平均最高产量分别为 $18,739 \mathrm{~kg} \mathrm{hm}^{-2}$ 和 $17,111 \mathrm{~kg} \mathrm{hm}^{-2}$, 产量较 D1 密度提高了 $32.2 \%$ (4562 $\left.\mathrm{kg} \mathrm{hm}^{-2}\right)$ 和 $27.7 \%\left(2725 \mathrm{~kg} \mathrm{hm}^{-2}\right)$; 就产量构成因素 来看, 穗粒数和百粒重与种植密度间存在极显著负 相关关系(表 2), 种植密度每增加 10,000 株 $\mathrm{hm}^{-2}$, 先玉 335 和东单 60 的穗粒数分别减少 27 粒和 28 粒，百粒重分别降低 $0.9 \mathrm{~g}$ 和 $1.0 \mathrm{~g}$; 先玉 335 的平 均百粒重较东单 60 高 $4.8 \mathrm{~g}$, 穗粒数在品种间无显 著性差异。 
表 1 密度对不同熟期玉米品种产量及其构成因素的影响

Table 1 Effects of plant density on yield and its components of maize hybrids with different maturity

\begin{tabular}{|c|c|c|c|c|c|c|}
\hline $\begin{array}{l}\text { 年份 } \\
\text { Year }\end{array}$ & $\begin{array}{c}\text { 品种 } \\
\text { Hybrids }\end{array}$ & $\begin{array}{c}\text { 密度 } \\
\text { Density }\end{array}$ & $\begin{array}{c}\text { 实收穗数 } \\
\text { Panicle number } \\
\left(\text { Ears hm }{ }^{-2}\right)\end{array}$ & $\begin{array}{c}\text { 穗粒数 } \\
\text { Grains per ear } \\
\left(\text { spike } \mathrm{hm}^{-2}\right)\end{array}$ & $\begin{array}{c}\text { 百粒重 } \\
\text { 100-kernel weight } \\
(\mathrm{g})\end{array}$ & $\begin{array}{c}\text { 籽粒产量 } \\
\text { Grain yield } \\
\left(\mathrm{kg} \mathrm{hm}^{-2}\right) \\
\end{array}$ \\
\hline \multirow[t]{8}{*}{2018} & 东单 60 & D1 & $46,354 \pm 564 \mathrm{~d}$ & $747 \pm 10.5 \mathrm{a}$ & $38.6 \pm 0.2 \mathrm{a}$ & $13,194 \pm 24 \mathrm{~d}$ \\
\hline & Dongdan 60 & D2 & $60,101 \pm 5321 \mathrm{c}$ & $700 \pm 4.5 \mathrm{~b}$ & $37.5 \pm 0.1 \mathrm{~b}$ & $14,128 \pm 167 \mathrm{c}$ \\
\hline & & D3 & $68,182 \pm 5463 \mathrm{~b}$ & $656 \pm 15.5 \mathrm{c}$ & $33.8 \pm 0.4 \mathrm{c}$ & $16,459 \pm 105 b$ \\
\hline & & D4 & $82,323 \pm 875 \mathrm{a}$ & $611 \pm 8.5 \mathrm{~d}$ & $32.8 \pm 0.9 \mathrm{~d}$ & $16,853 \pm 166 \mathrm{a}$ \\
\hline & 先玉 335 & D1 & $46,465 \pm 875 \mathrm{~d}$ & $748 \pm 11.3 \mathrm{a}$ & $42.5 \pm 1.6 \mathrm{a}$ & $14,179 \pm 142 \mathrm{~d}$ \\
\hline & Xianyu 335 & D2 & $56,061 \pm 1515 \mathrm{c}$ & $696 \pm 18.2 \mathrm{~b}$ & $41.0 \pm 1.5 \mathrm{~b}$ & $15,500 \pm 188 \mathrm{c}$ \\
\hline & & D3 & $65,152 \pm 1515 \mathrm{~b}$ & $656 \pm 9.6 \mathrm{c}$ & $39.6 \pm 0.9 \mathrm{c}$ & $18,010 \pm 88 \mathrm{~b}$ \\
\hline & & D4 & $80,324 \pm 358$ a & $633 \pm 10.5 \mathrm{~d}$ & $38.9 \pm 0.2 \mathrm{~d}$ & $18,741 \pm 107 \mathrm{a}$ \\
\hline \multirow[t]{8}{*}{2019} & 东单 60 & D1 & $46,308 \pm 744 \mathrm{~d}$ & $744 \pm 12.6 \mathrm{a}$ & $38.7 \pm 0.2 \mathrm{a}$ & $13,627 \pm 180 \mathrm{~d}$ \\
\hline & Dongdan 60 & D2 & $60,771 \pm 1936 \mathrm{c}$ & $696 \pm 10.5 \mathrm{~b}$ & $37.7 \pm 0.1 \mathrm{~b}$ & $15,276 \pm 245 \mathrm{c}$ \\
\hline & & D3 & $68,421 \pm 1419 \mathrm{~b}$ & $653 \pm 14.6 \mathrm{c}$ & $33.7 \pm 0.6 \mathrm{c}$ & $17,369 \pm 94 \mathrm{a}$ \\
\hline & & D4 & $81,774 \pm 355 \mathrm{a}$ & $611 \pm 18.3 \mathrm{~d}$ & $33.0 \pm 0.6 \mathrm{~d}$ & $16,976 \pm 135 b$ \\
\hline & 先玉 335 & D1 & $46,108 \pm 801 \mathrm{~d}$ & $742 \pm 12.9 \mathrm{a}$ & $42.5 \pm 0.3 \mathrm{a}$ & $14,599 \pm 128 \mathrm{c}$ \\
\hline & Xianyu 335 & D2 & $56,148 \pm 789 \mathrm{c}$ & $711 \pm 15.4 \mathrm{~b}$ & $41.3 \pm 0.1 \mathrm{~b}$ & $16,107 \pm 170 \mathrm{~b}$ \\
\hline & & D3 & $65,127 \pm 1980 \mathrm{~b}$ & $653 \pm 15.5 \mathrm{c}$ & $39.6 \pm 0.2 \mathrm{c}$ & $18,562 \pm 59 \mathrm{a}$ \\
\hline & & D4 & $80,165 \pm 999$ a & $624 \pm 8.4 \mathrm{~d}$ & $38.6 \pm 0.2 \mathrm{~d}$ & $18,737 \pm 81 \mathrm{a}$ \\
\hline 变异来源 & 年份 Year (Y) & & $\mathrm{ns}$ & ns & $\mathrm{ns}$ & ns \\
\hline \multirow[t]{6}{*}{ Source of variation } & 品种 Hybrid (H) & & ** & $\mathrm{ns}$ & ** & ** \\
\hline & 密度 Density (D) & & ** & ** & ** & ** \\
\hline & $\mathrm{Y} \times \mathrm{H}$ & & $\mathrm{ns}$ & ns & $\mathrm{ns}$ & $\mathrm{ns}$ \\
\hline & $\mathrm{Y} \times \mathrm{D}$ & & $\mathrm{ns}$ & ns & $\mathrm{ns}$ & ns \\
\hline & $\mathrm{Y} \times \mathrm{D}$ & & $* *$ & ${ }^{* *}$ & ** & ** \\
\hline & $\mathrm{Y} \times \mathrm{H} \times \mathrm{D}$ & & $\mathrm{ns}$ & ns & $\mathrm{ns}$ & ns \\
\hline
\end{tabular}

D1: 45,000 株 $\mathrm{hm}^{-2}$; D2: 60,000 株 $\mathrm{hm}^{-2}$; D3: 75,000 株 $\mathrm{hm}^{-2}$; D4: 90,000 株 $\mathrm{hm}^{-2}$ 。同列标以不同字母的值在处理间差异显著 $(P<0.05)$ 。 $\mathrm{ns}$ 表示差异性不显著, ${ }^{* *}$ 表示在 $P<0.01$ 水平上显著。

D1: 45,000 plants hm ${ }^{-2}$; D2: 60,000 plants $\mathrm{hm}^{-2}$; D3: 75,000 plants $\mathrm{hm}^{-2}$; D4: 90,000 plants $\mathrm{hm}^{-2}$. Values within the same column followed by different letters are significant difference at $P<0.05$ among different treatments. ns: not significant; ${ }^{* *}$ indicate significant differences at $P<0.01$.

表 2 不同熟期玉米产量构成因素与密度的回归关系

Table 2 Regression relationship between yield components and planting density in different maturity hybrids

\begin{tabular}{|c|c|c|c|}
\hline $\begin{array}{l}\text { 项目 } \\
\text { Item } \\
\end{array}$ & $\begin{array}{c}\text { 品种 } \\
\text { Hybrid } \\
\end{array}$ & $\begin{array}{c}\text { 回归方程 } \\
\text { Regression equation } \\
\end{array}$ & $\begin{array}{c}\text { 决定系数 } \\
R^{2}\end{array}$ \\
\hline 穗粒数 & 先玉 335 Xianyu 335 & $y=-0.0027 x+861.9$ & $0.987^{* *}$ \\
\hline Grains per spike & 东单 60 Dongdan 60 & $y=-0.0028 x+871.0$ & $0.998^{* *}$ \\
\hline 百粒重 & 先玉 335 Xianyu 335 & $y=-0.00009 x+46.3$ & $0.982^{* *}$ \\
\hline 100-kernel weight & 东单 60 Dongdan 60 & $y=-0.0001 x+45.2$ & $0.931^{* *}$ \\
\hline
\end{tabular}

** 表示在 $P<0.01$ 水平上显著。

** indicates significant differences at $P<0.01$.

2.2 不同熟期品种玉米的生育进程和有效积温 不同熟期玉米的生育期均随种植密度的增加而 缩短 (表 3)。不同熟期玉米生育进程和生育期内所需 积温不同，随着品种熟期的延长，生育期内所需积
温越多。先玉 335 和东单 60 的生育进程主要表现为 吐丝到生理成熟间的差异，东单 60 的生育期长，生 育期内所需积温较多。2018 年在 D4 种植密度下, 晚 熟品种东单 60 生育期内所需天数较中熟品种先玉 
表 3 不同熟期品种玉米的生育进程与有效积温需求情况

Table 3 Growth process and demand for effective accumulated temperature of different maturity maize hybrids

\begin{tabular}{|c|c|c|c|c|c|c|c|c|c|c|c|}
\hline $\begin{array}{l}\text { 年份 } \\
\text { Year }\end{array}$ & $\begin{array}{c}\text { 品种 } \\
\text { Hybrid }\end{array}$ & $\begin{array}{c}\text { 密度 } \\
\text { Density }\end{array}$ & $\begin{array}{c}\text { 播种期 } \\
\text { Sowing } \\
\text { date }(M / D) \\
\end{array}$ & $\begin{array}{c}\text { 吐丝期 } \\
\text { R1 } \\
(\mathrm{M} / \mathrm{D}) \\
\end{array}$ & $\begin{array}{c}\text { 生理成熟期 } \\
\text { R6 } \\
(\mathrm{M} / \mathrm{D})\end{array}$ & $\begin{array}{c}\text { 吐丝前天数 } \\
\text { Days before } \\
\text { silking (d) }\end{array}$ & $\begin{array}{c}\text { 吐丝前 } \\
\text { 有效积温 } \\
\text { EATBS }\left({ }^{\circ} \mathrm{C} \text { d) }\right. \\
\end{array}$ & $\begin{array}{l}\text { 吐丝后天数 } \\
\text { Days after } \\
\text { silking (d) }\end{array}$ & $\begin{array}{c}\text { 吐丝后 } \\
\text { 有效积温 } \\
\text { EATAS }\left({ }^{\circ} \mathrm{C}\right. \\
\end{array}$ & $\begin{array}{c}\text { 生育期 } \\
\text { Total } \\
\text { d) growth } \\
\end{array}$ & $\begin{array}{c}\text { 总有效积温 } \\
\text { TEAT } \\
\left({ }^{\circ} \mathrm{C} \text { d }\right)\end{array}$ \\
\hline \multirow[t]{8}{*}{2018} & 东单 60 & D1 & $4 / 30$ & $7 / 16$ & $9 / 27$ & 77 & 713.3 & 73 & 739.9 & 150 & 1453.2 \\
\hline & \multirow[t]{3}{*}{ Dongdan 60} & $\mathrm{D} 2$ & $4 / 30$ & $7 / 16$ & $9 / 26$ & 77 & 713.3 & 72 & 734.4 & 149 & 1447.7 \\
\hline & & D3 & $4 / 30$ & $7 / 16$ & $9 / 26$ & 77 & 713.3 & 72 & 734.4 & 149 & 1447.7 \\
\hline & & D4 & $4 / 30$ & $7 / 16$ & $9 / 25$ & 77 & 713.3 & 71 & 729.4 & 148 & 1442.7 \\
\hline & 先玉 335 & D1 & $4 / 30$ & $7 / 15$ & $9 / 22$ & 76 & 699.8 & 69 & 721.5 & 145 & 1421.3 \\
\hline & \multirow[t]{3}{*}{ Xianyu 335} & $\mathrm{D} 2$ & $4 / 30$ & $7 / 16$ & $9 / 22$ & 77 & 713.3 & 68 & 710.6 & 145 & 1423.9 \\
\hline & & D3 & $4 / 30$ & $7 / 16$ & $9 / 21$ & 77 & 713.3 & 67 & 704.8 & 144 & 1418.2 \\
\hline & & D4 & $4 / 30$ & $7 / 16$ & $9 / 20$ & 77 & 713.3 & 66 & 699.4 & 143 & 1412.7 \\
\hline \multirow[t]{8}{*}{2019} & 东单 60 & D1 & $4 / 29$ & $7 / 15$ & $9 / 25$ & 77 & 715.5 & 72 & 740.2 & 149 & 1455.8 \\
\hline & \multirow[t]{3}{*}{ Dongdan 60} & D2 & $4 / 29$ & $7 / 15$ & $9 / 25$ & 77 & 715.5 & 72 & 740.2 & 149 & 1455.8 \\
\hline & & D3 & $4 / 29$ & $7 / 15$ & $9 / 24$ & 77 & 715.5 & 71 & 734.1 & 148 & 1449.7 \\
\hline & & D4 & $4 / 29$ & $7 / 15$ & $9 / 23$ & 77 & 715.5 & 70 & 728.1 & 147 & 1443.6 \\
\hline & 先玉 335 & D1 & $4 / 29$ & $7 / 14$ & $9 / 22$ & 76 & 702.0 & 69 & 729.2 & 145 & 1431.3 \\
\hline & \multirow[t]{3}{*}{ Xianyu 335} & D2 & $4 / 29$ & $7 / 15$ & $9 / 21$ & 77 & 715.5 & 68 & 715.7 & 145 & 1431.3 \\
\hline & & D3 & $4 / 29$ & $7 / 15$ & $9 / 20$ & 77 & 715.5 & 67 & 710.3 & 144 & 1425.8 \\
\hline & & D4 & $4 / 29$ & $7 / 15$ & $9 / 19$ & 77 & 715.5 & 66 & 705.4 & 143 & 1420.9 \\
\hline
\end{tabular}

D1: 45,000 株 $\mathrm{hm}^{-2} ; \mathrm{D} 2: 60,000$ 株 $\mathrm{hm}^{-2} ; \mathrm{D} 3: 75,000$ 株 $\mathrm{hm}^{-2} ; \mathrm{D} 4: 90,000$ 株 $\mathrm{hm}^{-2}$ 。

D1: 45,000 plants hm ${ }^{-2}$; D2: 60,000 plants $\mathrm{hm}^{-2}$; D3: 75,000 plants $\mathrm{hm}^{-2}$; D4: 90,000 plants $\mathrm{hm}^{-2}$. M/D: month/day; R1: date of silking stage; R6: date of physiological maturity. EATBS: effective accumulated temperature before silking; EATAS: effective accumulated temperature after silking; TEAT: total effective accumulated temperature.

335 多 $5 \mathrm{~d} ; 2019$ 年在 D4 种植密度下，晚熟品种东单 60 生育期内所需天数较中熟品种先玉 335 多 $4 \mathrm{~d}$, 说 明先玉 335 具有更多的时间进行脱水。

\section{3 密度对不同熟期玉米品种不同粒位籽粒灌} 浆参数影响

不同粒位的籽粒百粒重和灌浆速率随种植密度 的增加均呈下降的趋势(图 2 和图 3), 不同粒位籽粒 灌浆速率和百粒重均表现为先玉 $335>$ 东单 60, 先 玉 335 达到灌浆速率峰值的时间早于东单 60 , 达到 灌浆速率峰值前, 先玉 335 的灌浆速率上升较快, 超过峰值后先玉 335 灌浆速率下降较快。随着粒位 的上升, 百粒重和灌浆速率均呈下降趋势, 下部籽 粒百粒重整个生育期内高于上部籽粒，在灌浆 $55 \mathrm{~d}$ 左右粒重差距最大, 且达到灌浆速率峰值较早, 在 灌浆后期下部籽粒灌浆速率高于下部籽粒, 但此时 的灌浆速率很低, 且灌浆时间较短, 短时间内积累 的籽粒干物质以难以弥补灌浆前中期的粒重差距。

由表 4 可知, 随着品种熟期的延长, 不同玉米 不同粒位的籽粒灌浆参数呈现规律性变化，其中以 先玉 335 的灌浆参数最为优越, 且增加种植密度会
限制不同粒位籽粒灌浆过程，影响籽粒粒重。运用 Logistics 模型能较好的模拟不同粒位的籽粒灌浆过 程, 决定系数 $\left(R^{2}\right)$ 均在 $0.996 \sim 0.998$ 之间。灌浆参数 在品种和粒位间均存在差异。与上部籽粒相比, 下 部籽粒 $G_{\max } 、 G_{\mathrm{mean}} 、 W_{\max }$ 较上部籽粒大, $T_{\max } 、 D$ 短; 品种间, 随着品种熟期的延长, $T_{\max } 、 D$ 延长, 而 $G_{\max } 、 G_{\text {mean }} 、 W_{\text {max }}$ 较小。随着种植密度的增加, 不 同粒位籽粒灌浆的 $T_{\max } 、 W_{\max } 、 G_{\max } 、 G_{\text {mean }} 、 D$ 均 呈下降趋势。与 D1 种植密度相比, 在 D4 种植密度 下先玉 335 和东单 60 下部籽粒的 $D$ 分别减少 $3.2 \mathrm{~d}$ 和 $1.8 \mathrm{~d}, G_{\text {mean }}$ 分别降低 $0.08 \mathrm{~g} \mathrm{~d}^{-1}$ 和 $0.07 \mathrm{~g} \mathrm{~d}^{-1}, T_{\text {max }}$ 分别减少 $0.6 \mathrm{~d}$ 和 $0.6 \mathrm{~d}$; 上部籽粒的 $D$ 分别减少 3.5 $\mathrm{d}$ 和 $2.4 \mathrm{~d}, G_{\text {mean }}$ 分别降低 $0.08 \mathrm{~g} \mathrm{~d}^{-1}$ 和 $0.06 \mathrm{~g} \mathrm{~d}^{-1}, T_{\max }$ 分别减少 $0.6 \mathrm{~d}$ 和 $0.4 \mathrm{~d}$ 。在 $\mathrm{D} 4$ 处理下, 先玉 335 下 部和上部籽粒的 $T_{\max }$ 较东单 60 早 $2.2 \mathrm{~d}$ 和 $2.3 \mathrm{~d}, G_{\text {mean }}$ 较东单 60 高 $0.08 \mathrm{~g} \mathrm{~d}^{-1}$ 和 $0.04 \mathrm{~g} \mathrm{~d}^{-1}$ 。

2.4 密度对不同熟期玉米不同粒位籽粒脱水的 影响

方差分析(表 5)显示，年份、品种、粒位以及品 种和种植密度的交互、品种和粒位的交互以及品种、 


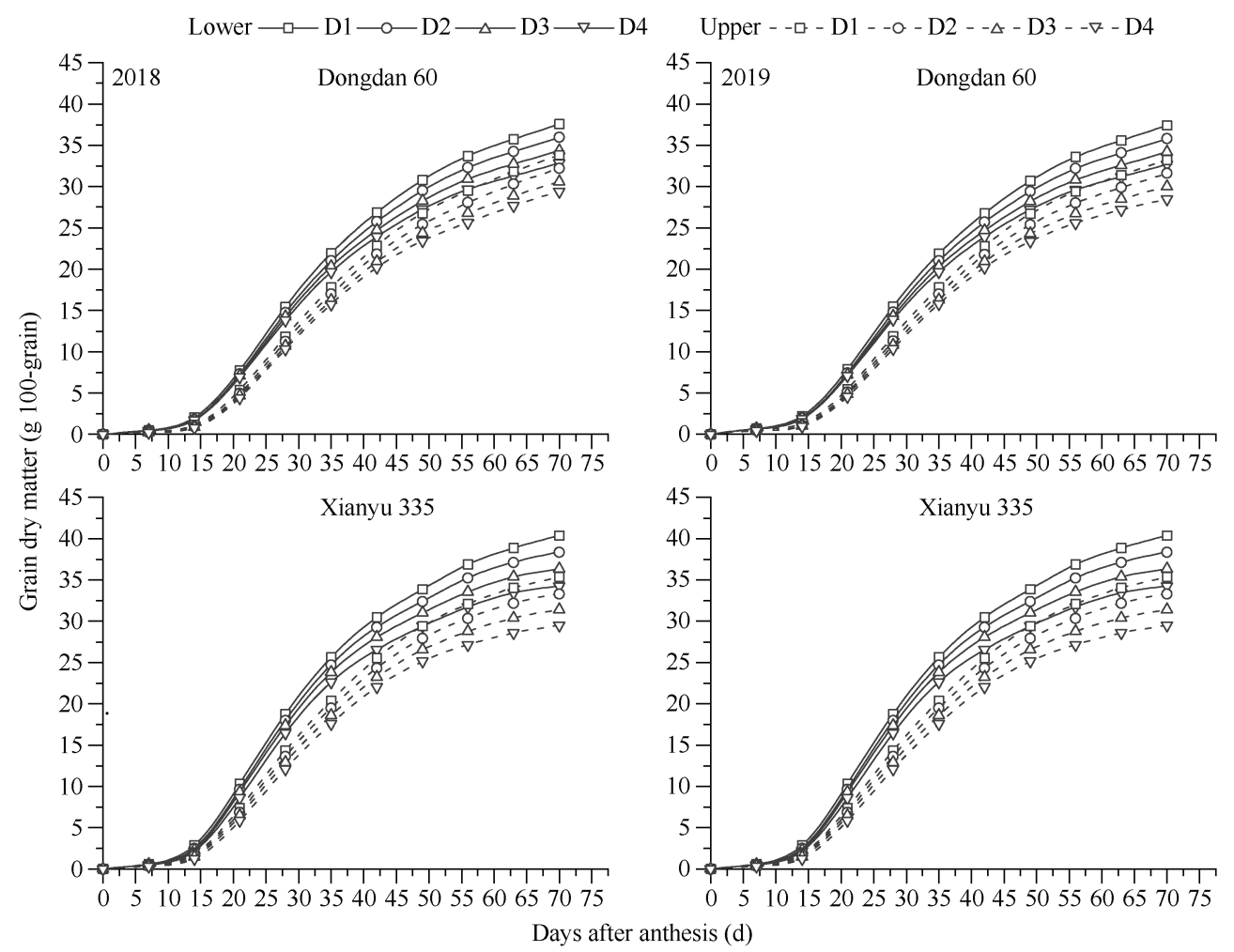

图 2 密度对不同熟期品种玉米不同粒位籽粒粒重的影响

Fig. 2 Effects of plant density on grain weight of upper kernels and lower kernels in different maturity maize hybrids 处理同表 1 。Treatments are the same as those given in Table 1 .

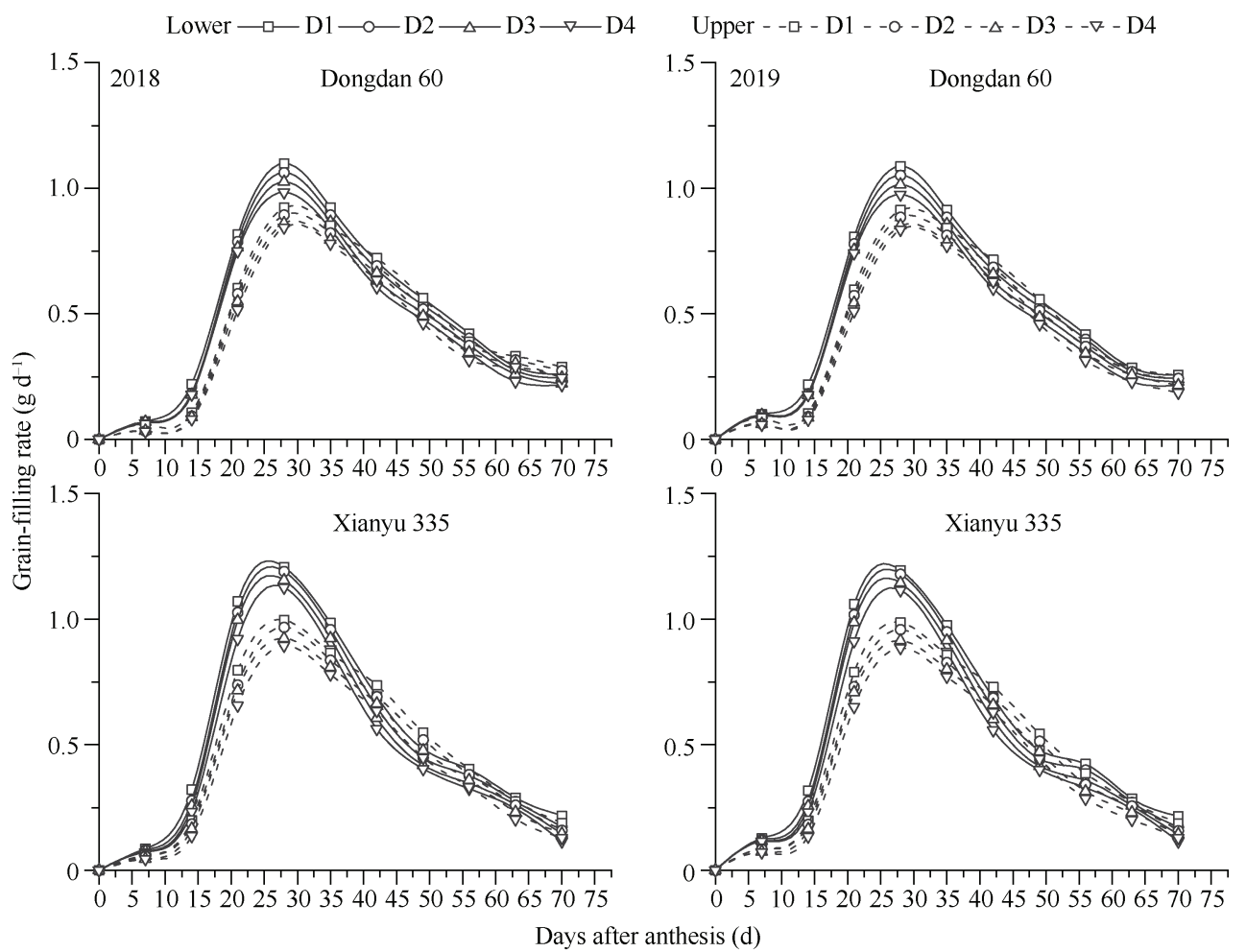

图 3 密度对不同熟期品种玉米不同粒位籽粒灌浆速率的影响

Fig. 3 Effects of plant density on grain filling rate of upper kernels and lower kernels in different maturity maize hybrids 处理同表 1 。Treatments are the same as those given in Table 1. 
表 4 密度对不同熟期玉米不同粒位籽粒灌浆参数的影响

Table 4 Effect of plant density on grain filling parameters of upper and lower kernels in different maturity maize hybrids

\begin{tabular}{|c|c|c|c|c|c|c|c|c|c|c|c|c|}
\hline $\begin{array}{l}\text { 年份 } \\
\text { Year }\end{array}$ & $\begin{array}{c}\text { 品种 } \\
\text { Hybrid }\end{array}$ & $\begin{array}{c}\text { 粒位 } \\
\text { Grain position }\end{array}$ & $\begin{array}{c}\text { 密度 } \\
\text { Density }\end{array}$ & $\begin{array}{l}T_{\max } \\
\text { (d) }\end{array}$ & $\begin{array}{c}G_{\max } \\
\left(\mathrm{g} \mathrm{d}^{-1}\right)\end{array}$ & $\begin{array}{c}G_{\text {mean }} \\
\left(\mathrm{g} \mathrm{d}^{-1}\right)\end{array}$ & $\begin{array}{l}D \\
(\mathrm{~d})\end{array}$ & $\begin{array}{c}W_{\max } \\
(\mathrm{g})\end{array}$ & $a$ & $b$ & $c$ & $\begin{array}{c}\text { 决定系数 } \\
R^{2}\end{array}$ \\
\hline \multirow[t]{16}{*}{2018} & 东单 60 & 下部 & D1 & 32.2 & 1.07 & 0.72 & 51.0 & 18.3 & 36.5 & 44.1 & 0.118 & 0.997 \\
\hline & Dongdan 60 & Lower & D2 & 32.2 & 1.04 & 0.69 & 50.5 & 17.5 & 34.9 & 46.0 & 0.119 & 0.997 \\
\hline & & & D3 & 32.0 & 1.00 & 0.67 & 50.0 & 16.6 & 33.3 & 46.3 & 0.120 & 0.997 \\
\hline & & & D4 & 31.6 & 0.97 & 0.65 & 49.2 & 15.9 & 31.8 & 47.0 & 0.122 & 0.997 \\
\hline & & 上部 & D1 & 34.5 & 0.95 & 0.63 & 52.1 & 16.5 & 33.0 & 53.6 & 0.115 & 0.997 \\
\hline & & Upper & D2 & 34.5 & 0.92 & 0.61 & 51.2 & 15.7 & 31.3 & 57.1 & 0.117 & 0.997 \\
\hline & & & D3 & 34.3 & 0.88 & 0.59 & 50.5 & 14.9 & 29.7 & 59.0 & 0.119 & 0.997 \\
\hline & & & D4 & 34.1 & 0.86 & 0.57 & 49.6 & 14.2 & 28.4 & 61.8 & 0.121 & 0.997 \\
\hline & 先玉 335 & 下部 & D1 & 30.1 & 1.20 & 0.80 & 49.0 & 19.5 & 39.0 & 39.8 & 0.123 & 0.996 \\
\hline & Xianyu 335 & Lower & D2 & 29.8 & 1.17 & 0.78 & 47.6 & 18.5 & 37.6 & 43.1 & 0.126 & 0.996 \\
\hline & & & D3 & 29.5 & 1.14 & 0.76 & 46.4 & 17.6 & 35.6 & 45.4 & 0.129 & 0.996 \\
\hline & & & D4 & 29.4 & 1.09 & 0.72 & 45.7 & 16.6 & 33.6 & 47.6 & 0.131 & 0.997 \\
\hline & & 上部 & D1 & 32.4 & 1.03 & 0.69 & 50.6 & 17.3 & 34.6 & 46.7 & 0.119 & 0.997 \\
\hline & & Upper & D2 & 32.2 & 0.99 & 0.66 & 49.5 & 16.3 & 33.2 & 49.2 & 0.121 & 0.998 \\
\hline & & & D3 & 31.9 & 0.95 & 0.64 & 48.3 & 15.4 & 31.2 & 52.8 & 0.124 & 0.998 \\
\hline & & & D4 & 31.8 & 0.92 & 0.61 & 47.0 & 14.4 & 29.3 & 58.0 & 0.128 & 0.998 \\
\hline \multirow[t]{16}{*}{2019} & 东单 60 & 下部 & D1 & 32.1 & 1.05 & 0.70 & 52.1 & 18.2 & 36.5 & 40.4 & 0.115 & 0.997 \\
\hline & Dongdan 60 & Lower & D2 & 32.1 & 1.01 & 0.68 & 51.6 & 17.4 & 34.9 & 42.1 & 0.116 & 0.997 \\
\hline & & & D3 & 31.9 & 0.98 & 0.65 & 51.1 & 16.6 & 33.3 & 42.3 & 0.117 & 0.997 \\
\hline & & & D4 & 31.5 & 0.95 & 0.63 & 50.4 & 15.9 & 31.8 & 42.8 & 0.119 & 0.997 \\
\hline & & 上部 & D1 & 34.1 & 0.94 & 0.63 & 52.0 & 16.3 & 32.5 & 51.3 & 0.115 & 0.997 \\
\hline & & Upper & D2 & 34.2 & 0.91 & 0.60 & 51.0 & 15.4 & 30.9 & 54.8 & 0.118 & 0.997 \\
\hline & & & D3 & 33.9 & 0.87 & 0.58 & 50.3 & 14.7 & 29.3 & 56.6 & 0.119 & 0.997 \\
\hline & & & D4 & 33.5 & 0.85 & 0.57 & 48.8 & 13.9 & 27.8 & 61.2 & 0.123 & 0.997 \\
\hline & 先玉 335 & 下部 & D1 & 30.0 & 1.17 & 0.78 & 50.3 & 19.5 & 39.1 & 35.7 & 0.119 & 0.996 \\
\hline & Xianyu 335 & Lower & D2 & 29.7 & 1.14 & 0.76 & 48.9 & 18.6 & 37.1 & 38.5 & 0.123 & 0.996 \\
\hline & & & D3 & 29.4 & 1.11 & 0.74 & 47.7 & 17.6 & 35.2 & 40.4 & 0.126 & 0.996 \\
\hline & & & D4 & 29.3 & 1.06 & 0.71 & 46.9 & 16.6 & 33.2 & 42.4 & 0.128 & 0.997 \\
\hline & & 上部 & D1 & 32.3 & 1.01 & 0.67 & 51.6 & 17.3 & 34.6 & 42.7 & 0.116 & 0.997 \\
\hline & & Upper & D2 & 32.1 & 0.97 & 0.65 & 50.6 & 16.3 & 32.6 & 45.0 & 0.118 & 0.998 \\
\hline & & & D3 & 31.8 & 0.93 & 0.62 & 49.3 & 15.4 & 30.7 & 48.1 & 0.122 & 0.998 \\
\hline & & & D4 & 31.7 & 0.90 & 0.60 & 48.0 & 14.4 & 28.8 & 52.7 & 0.125 & 0.998 \\
\hline
\end{tabular}

处理同表 $1 。 a 、 b 、 c$ 为模型参数; $T_{\max }$ ：灌浆速率达到最大时需要的天数; $W_{\max }$ ：灌浆速率达到最大值的粒重; $G_{\max }$ : 籽粒最大灌浆速率; $G_{\text {mean }}$ : 平均灌浆速率; $D$ : 籽粒活跃灌浆期。

Treatments are the same as those given in Table 1. $a, b$, and $c$ are the model parameters; $T_{\max }$ : times needed for reaching the maximum grain-filling rate; $W_{\max }$ : kernel weight at the maximum grain-filling rate; $G_{\max }$ : maximum grain-filling rate; $G_{\operatorname{mean}}$ : mean grain-filling rate; $D$ : active grain-filling stage.

种植密度、粒位三者的交互作用均达到显著水平。 不同熟期玉米不同粒位的籽粒生理成熟时的籽粒含 水率和总脱水速率存在显著差异(表 6)。先玉 335 和 东单 60 下部籽粒生理成熟时平均含水率较上部籽 粒高 $0.5 \%$ 和 $1.3 \%$ ，总脱水速率较上部籽粒低 $0.005 \%{ }^{\circ} \mathrm{C} \mathrm{d}^{-1}$ 和 $0.002{ }^{\circ} \mathrm{C} \mathrm{d}^{-1}$; 品种间, 先玉 335
下部和上部籽粒生理成熟时籽粒含水率较东单 60 低 $2.3 \%$ 和 $1.5 \%$, 总脱水速率较东单 60 高 $0.006 \%{ }^{\circ} \mathrm{C}$ $\mathrm{d}^{-1}$ 和 $0.005 \%{ }^{\circ} \mathrm{C} \mathrm{d}^{-1}$; 随着种植密度的增加, 生理成 熟时不同熟期品种玉米不同粒位的籽粒含水率降 低, 总脱水速率加快; 与 $\mathrm{D} 1$ 密度相比, D4 密度下部 籽粒总脱水速率分别增加(先玉 335) $0.006 \%{ }^{\circ} \mathrm{C} \mathrm{d}^{-1}$ 和 
表 5 不同熟期品种玉米䊏粒含水率方差分析

Table 5 Analysis of variance of moisture content of maize with different maturity hybrids

\begin{tabular}{|c|c|c|c|c|}
\hline $\begin{array}{c}\text { 变异来源 } \\
\text { Source of variation }\end{array}$ & $\begin{array}{c}\text { 平方和 } \\
\text { Sum of squares }\end{array}$ & $\begin{array}{c}\text { 自由度 } \\
\text { Degrees freedom }\end{array}$ & $\begin{array}{c}\text { 均方 } \\
\text { Mean square }\end{array}$ & $\begin{array}{c}F \text { 值 } \\
F \text {-value } \\
\end{array}$ \\
\hline 年份 Year (Y) & 1.16 & 1 & 1.16 & $146.05^{* *}$ \\
\hline 品种 Hybrid $(\mathrm{H})$ & 5.45 & 1 & 5.45 & $683.78^{* *}$ \\
\hline 密度 Density (D) & 28.13 & 3 & 9.38 & $1176.76^{* *}$ \\
\hline 粒位 Grain position (GP) & 130.93 & 1 & 130.93 & $16,433.32^{* *}$ \\
\hline $\mathrm{Y} \times \mathrm{H}$ & 0.12 & 1 & 0.12 & $15.38^{* *}$ \\
\hline $\mathrm{Y} \times \mathrm{D}$ & 0.01 & 3 & 0.01 & 0.43 \\
\hline $\mathrm{Y} \times \mathrm{GP}$ & 0.13 & 1 & 0.13 & $16.28^{* *}$ \\
\hline $\mathrm{H} \times \mathrm{D}$ & 0.10 & 3 & 0.03 & $4.04^{* *}$ \\
\hline $\mathrm{H} \times \mathrm{GP}$ & 101.87 & 1 & 101.87 & $12,786.23^{* *}$ \\
\hline $\mathrm{D} \times \mathrm{GP}$ & 0.22 & 3 & 0.07 & $9.37^{* *}$ \\
\hline $\mathrm{Y} \times \mathrm{H} \times \mathrm{D}$ & 0.01 & 3 & 0.01 & 0.38 \\
\hline $\mathrm{Y} \times \mathrm{H} \times \mathrm{GP}$ & 0.15 & 1 & 0.15 & $18.59^{* *}$ \\
\hline $\mathrm{Y} \times \mathrm{D} \times \mathrm{GP}$ & 0.01 & 3 & 0.01 & 0.29 \\
\hline $\mathrm{H} \times \mathrm{D} \times \mathrm{GP}$ & 0.78 & 3 & 0.26 & $32.67^{* *}$ \\
\hline $\mathrm{Y} \times \mathrm{H} \times \mathrm{D} \times \mathrm{GP}$ & 0.01 & 3 & 0.01 & 0.18 \\
\hline 误差 Error & 0.51 & 64 & 0.01 & \\
\hline 总变异 Total variation & $84,066.82$ & 96 & & \\
\hline
\end{tabular}

"*表示在 0.01 水平上差异显著。

${ }^{* *}$ indicates significant differences at the 0.01 probability level.

表 6 密度对不同熟期玉米不同粒位籽粒脱水速率的影响

Table 6 Effects of plant density on the dehydration rate of upper and lower kernels in different maturity maize hybrids

\begin{tabular}{|c|c|c|c|c|c|c|c|c|}
\hline \multirow[b]{2}{*}{$\begin{array}{c}\text { 品种 } \\
\text { Hybrid }\end{array}$} & \multirow[b]{2}{*}{$\begin{array}{c}\text { 粒位 } \\
\text { Grain position }\end{array}$} & \multirow[b]{2}{*}{$\begin{array}{c}\text { 密度 } \\
\text { Density }\end{array}$} & \multicolumn{3}{|c|}{2018} & \multicolumn{3}{|c|}{2019} \\
\hline & & & 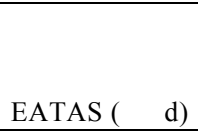 & $\begin{array}{c}\text { 生理成熟时籽粒 } \\
\text { 含水率 } \\
\text { GMCPM }(\%)\end{array}$ & $\begin{array}{c}\text { 总脱水速率 } \\
\text { TDR } \\
\left(\%{ }^{\circ} \mathrm{Cd}^{-1}\right) \\
\end{array}$ & $\begin{array}{l}\text { 吐丝后有效积 } \\
\text { 积温 } \\
\text { EATAS }\left({ }^{\circ} \mathrm{C} \text { d }\right)\end{array}$ & $\begin{array}{c}\text { 生理成熟时籽粒 } \\
\text { 含水率 } \\
\text { GMCPM (\%) }\end{array}$ & $\begin{array}{c}\text { 总脱水速率 } \\
\text { TDR } \\
\left(\%{ }^{\circ} \mathrm{C} \mathrm{d}^{-1}\right) \\
\end{array}$ \\
\hline 东单 60 & 下部 & D1 & 739.9 & $32.9 \mathrm{a}$ & $0.078 \mathrm{c}$ & 740.2 & $32.6 \mathrm{a}$ & $0.077 \mathrm{c}$ \\
\hline \multirow[t]{7}{*}{ Dongdan 60} & Lower & D2 & 734.4 & $32.5 \mathrm{a}$ & $0.078 \mathrm{c}$ & 740.2 & $32.2 \mathrm{a}$ & $0.078 \mathrm{c}$ \\
\hline & & D3 & 734.4 & $31.9 \mathrm{a}$ & $0.080 \mathrm{c}$ & 734.1 & $31.6 \mathrm{a}$ & $0.079 \mathrm{c}$ \\
\hline & & D4 & 729.4 & $31.2 \mathrm{~b}$ & $0.081 \mathrm{~b}$ & 728.1 & $30.9 \mathrm{~b}$ & $0.081 \mathrm{~b}$ \\
\hline & 上部 & D1 & 739.9 & $31.9 \mathrm{a}$ & $0.079 \mathrm{c}$ & 740.2 & $31.6 \mathrm{a}$ & $0.079 \mathrm{c}$ \\
\hline & Upper & D2 & 734.4 & $31.0 \mathrm{~b}$ & $0.080 \mathrm{~b}$ & 740.2 & $30.7 \mathrm{~b}$ & $0.080 \mathrm{~b}$ \\
\hline & & D3 & 734.4 & $30.5 \mathrm{~b}$ & $0.081 \mathrm{~b}$ & 734.1 & $30.2 \mathrm{c}$ & $0.081 \mathrm{~b}$ \\
\hline & & D4 & 729.4 & $30.1 \mathrm{c}$ & $0.083 \mathrm{a}$ & 728.1 & $29.8 \mathrm{c}$ & $0.082 \mathrm{a}$ \\
\hline 先玉 335 & 下部 & D1 & 721.5 & $30.8 \mathrm{~b}$ & $0.082 \mathrm{~d}$ & 729.2 & $30.5 \mathrm{~b}$ & $0.082 \mathrm{~d}$ \\
\hline \multirow[t]{7}{*}{ Xianyu 335} & Lower & D2 & 710.6 & $30.4 \mathrm{c}$ & $0.084 \mathrm{~d}$ & 715.7 & $30.1 \mathrm{c}$ & $0.084 \mathrm{~d}$ \\
\hline & & D3 & 704.8 & $29.3 \mathrm{~d}$ & $0.086 \mathrm{~b}$ & 710.3 & $29.0 \mathrm{~d}$ & $0.086 \mathrm{~b}$ \\
\hline & & D4 & 699.4 & $28.8 \mathrm{~d}$ & $0.087 \mathrm{a}$ & 705.4 & $28.5 \mathrm{~d}$ & $0.088 \mathrm{a}$ \\
\hline & 上部 & D1 & 721.5 & $30.0 \mathrm{c}$ & $0.083 \mathrm{~d}$ & 729.2 & $29.7 \mathrm{c}$ & $0.083 \mathrm{~d}$ \\
\hline & Upper & D2 & 710.6 & $29.7 \mathrm{~d}$ & $0.085 \mathrm{c}$ & 715.7 & $29.4 \mathrm{~d}$ & $0.085 \mathrm{c}$ \\
\hline & & D3 & 704.8 & $29.1 \mathrm{~d}$ & $0.086 \mathrm{~b}$ & 710.3 & $28.9 \mathrm{~d}$ & $0.086 \mathrm{~b}$ \\
\hline & & D4 & 699.4 & $28.5 \mathrm{~d}$ & $0.088 \mathrm{a}$ & 705.4 & $28.2 \mathrm{~d}$ & $0.088 \mathrm{a}$ \\
\hline
\end{tabular}

处理同表 1 。同列标以不同小写字母的值达到 0.05 显著差异。

Treatments are the same as those given in Table 1. EATAS: effective accumulated temperature after silking; GMCPM: grain moisture content at physiological maturity; TDR: total dehydration rate. Values followed by different lowercase letter within a column are significantly different at the 0.05 probability level. 
(东单 60 ) $0.004 \%{ }^{\circ} \mathrm{C} \mathrm{d}$, 上部籽粒分别增加(先玉 335) $0.005 \%{ }^{\circ} \mathrm{C} \mathrm{d} \mathrm{d}^{-1}$ 和(东单 60) $0.004 \%{ }^{\circ} \mathrm{C} \mathrm{d}^{-1}$ 。

2.5 密度对不同熟期玉米不同粒位籽粒脱水的 影响

籽粒含水率达到机收标准所需积温情况受品 种、粒位以及种植密度影响(表 7)。与下部籽粒相比,
上部籽粒自吐丝至含水率降至 $28 \%$ 和 $25 \%$ 时所需 积温较少, 并且籽粒含水率从 $28 \%$ 降至 $25 \%$ 所需积 温较少; 品种间, 先玉 335 籽粒含水率降至 28\%和 $25 \%$ 较东单 60 所需有效积温平均减少 $10.2^{\circ} \mathrm{C} \mathrm{d}$ 和 $14.0^{\circ} \mathrm{C} \mathrm{d}$; 随着种植密度的增加, 不同熟期品种玉米 下部和上部籽粒含水率降至 $28 \%$ 和 $25 \%$ 所需积温减

\section{表 7 不同熟期品种玉米不同粒位籽粒 Logistic power 模型拟合结果}

Table 7 Fitting results of Logistic power model of upper and lower kernels in different maturity maize hybrids

\begin{tabular}{|c|c|c|c|c|c|c|c|c|c|}
\hline $\begin{array}{l}\text { 年份 } \\
\text { Year }\end{array}$ & $\begin{array}{c}\text { 品种 } \\
\text { Hybrid }\end{array}$ & $\begin{array}{c}\text { 粒位 } \\
\text { Grain } \\
\text { position }\end{array}$ & $\begin{array}{c}\text { 密度 } \\
\text { Density }\end{array}$ & $a$ & $b$ & $c$ & $\begin{array}{c}\text { 决定系数 } \\
R^{2}\end{array}$ & $\begin{array}{c}\text { 吐丝-含水率 } 28 \% \text { 所需 } \\
\text { 有效积温 } \\
\text { Effective accumulated } \\
\text { temperature from silking to } \\
28 \% \mathrm{MC}\left({ }^{\circ} \mathrm{C} \text { d) }\right.\end{array}$ & $\begin{array}{c}\text { 吐丝-含水率 } 25 \% \text { 所需 } \\
\text { 有效积温 } \\
\text { Effective accumulated } \\
\text { temperature from silking to } \\
25 \% \mathrm{MC}\left({ }^{\circ} \mathrm{C} \text { d) }\right.\end{array}$ \\
\hline \multirow[t]{16}{*}{2018} & 东单 60 & 下部 & D1 & 96.1 & 506.2 & 1.85 & 0.993 & 817.2 & 889.2 \\
\hline & Dongdan 60 & Lower & D2 & 95.7 & 508.9 & 1.97 & 0.994 & 796.3 & 862.2 \\
\hline & & & D3 & 95.5 & 506.7 & 2.04 & 0.994 & 780.1 & 842.4 \\
\hline & & & D4 & 95.3 & 504.6 & 2.09 & 0.995 & 767.7 & 827.6 \\
\hline & & 上部 & D1 & 94.5 & 525.1 & 2.17 & 0.995 & 782.3 & 841.1 \\
\hline & & Upper & D2 & 95.2 & 512.2 & 2.18 & 0.994 & 764.7 & 821.8 \\
\hline & & & D3 & 94.9 & 512.2 & 2.27 & 0.994 & 751.7 & 805.6 \\
\hline & & & D4 & 94.7 & 508.8 & 2.35 & 0.995 & 736.5 & 787.6 \\
\hline & 先玉 335 & 下部 & D1 & 93.7 & 521.7 & 1.99 & 0.995 & 800.6 & 866.7 \\
\hline & Xianyu 335 & Lower & D2 & 94.0 & 518.0 & 2.05 & 0.995 & 787.4 & 850.5 \\
\hline & & & D3 & 93.9 & 512.5 & 2.11 & 0.995 & 768.9 & 828.6 \\
\hline & & & D4 & 93.9 & 512.4 & 2.20 & 0.996 & 756.8 & 813.2 \\
\hline & & 上部 & D1 & 92.9 & 530.5 & 2.25 & 0.998 & 770.1 & 826.2 \\
\hline & & Upper & D2 & 93.4 & 527.6 & 2.34 & 0.996 & 758.3 & 811.5 \\
\hline & & & D3 & 92.9 & 530.5 & 2.48 & 0.997 & 744.4 & 793.6 \\
\hline & & & D4 & 93.1 & 523.9 & 2.56 & 0.997 & 728.1 & 774.5 \\
\hline \multirow[t]{16}{*}{2019} & 东单 60 & 下部 & D1 & 95.4 & 444.0 & 1.85 & 0.994 & 820.2 & 894.7 \\
\hline & Dongdan 60 & Lower & D2 & 95.1 & 446.5 & 1.97 & 0.995 & 798.8 & 866.8 \\
\hline & & & D3 & 94.9 & 444.7 & 2.04 & 0.995 & 782.3 & 846.5 \\
\hline & & & D4 & 94.6 & 442.9 & 2.09 & 0.996 & 769.7 & 831.4 \\
\hline & & 上部 & D1 & 93.9 & 460.8 & 2.17 & 0.995 & 784.8 & 845.5 \\
\hline & & Upper & D2 & 94.5 & 449.6 & 2.18 & 0.995 & 766.8 & 825.6 \\
\hline & & & D3 & 94.3 & 449.8 & 2.27 & 0.995 & 753.6 & 809.0 \\
\hline & & & D4 & 94.0 & 446.8 & 2.35 & 0.996 & 738.2 & 790.8 \\
\hline & 先玉 335 & 下部 & D1 & 93.1 & 457.3 & 1.98 & 0.995 & 803.8 & 872.3 \\
\hline & Xianyu 335 & Lower & D2 & 93.4 & 454.2 & 2.04 & 0.995 & 790.1 & 855.4 \\
\hline & & & D3 & 94.4 & 444.2 & 2.07 & 0.995 & 771.3 & 833.0 \\
\hline & & & D4 & 94.5 & 443.8 & 2.15 & 0.996 & 758.9 & 817.1 \\
\hline & & 上部 & D1 & 92.3 & 465.4 & 2.25 & 0.997 & 772.7 & 830.7 \\
\hline & & Upper & D2 & 92.8 & 463.0 & 2.33 & 0.996 & 760.7 & 815.5 \\
\hline & & & D3 & 92.3 & 465.8 & 2.48 & 0.997 & 746.5 & 797.2 \\
\hline & & & D4 & 92.5 & 460.2 & 2.57 & 0.998 & 729.7 & 777.6 \\
\hline
\end{tabular}


少。与 D1 种植密度相比, 在 D4 种植密度下先玉 335 和东单 60 的下部籽粒含水率降至 $28 \%$ 时所需有效积 温减少 $44.3^{\circ} \mathrm{C} \mathrm{d}$ 和 $50.0^{\circ} \mathrm{C} \mathrm{d}$, 含水率降至 $25 \%$ 时所 需有效积温分别减 $54.3^{\circ} \mathrm{Cd}$ 和 $62.4^{\circ} \mathrm{C} \mathrm{d}$, 上部籽粒 含水率降至 $28 \%$ 时所需有效积温分别减少 $42.4^{\circ} \mathrm{C} \mathrm{d}$ 和 $46.2^{\circ} \mathrm{C} \mathrm{d}$, 含水率降至 $25 \%$ 时所需有效积温分别 减少 $52.4^{\circ} \mathrm{C} d$ 和 $54.1^{\circ} \mathrm{C} \mathrm{d}$ 。

\section{6 不同粒位籽粒灌浆和脱水特性的相关性分} 析

不同粒位籽粒总脱水特性与灌浆参数之间的相 关关系表现出大致相同的趋势(图 4)。下部籽粒和上
部籽粒总脱水速率均与平均灌浆速率 $(0.39,-0.01)$ 无 显著相关关系, 与活跃灌浆期 $(0.99, P<0.01 ;-0.97$, $P<0.01)$ 、生理成熟时籽粒含水率 $(-0.99, P<0.01$; $-0.96, P<0.01)$ 、吐丝到生理成熟时有效积温 $(-0.99$, $P<0.01 ;-0.90, P<0.01)$ 呈极显著负相关关系; 其中 下部籽粒总脱水速率与粒重无显著相关关系 $(-0.38)$, 而上部籽粒与粒重呈显著负相关关系 $(-0.74, P<$ $0.05)$; 生理成熟时不同粒位籽粒含水率与吐丝到生 理成熟时有效积温 $(0.99, P<0.01 ; 0.96, P<0.01)$ 和活 跃灌浆期 $(0.99, P<0.01 ; 0.99, P<0.01)$ 呈极显著正相 关关系。
A

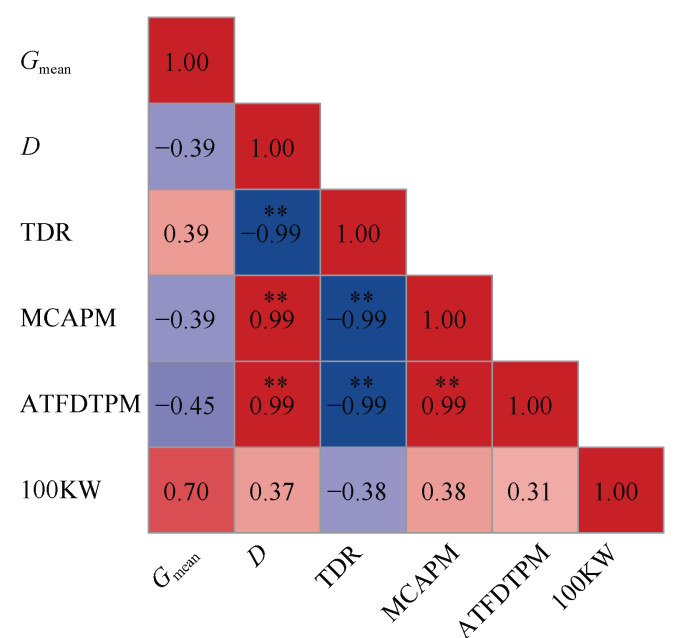

B

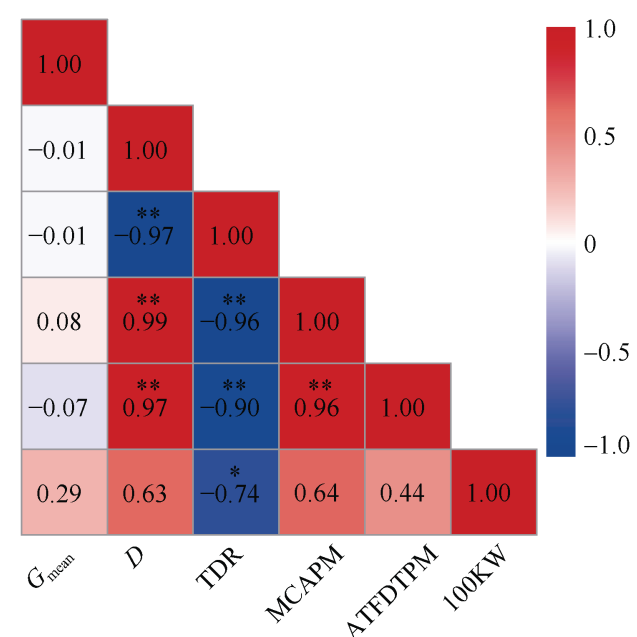

图 4 不同粒位籽粒灌浆参数与脱水速率相关性分析

Fig.4 Correlation analysis of grain filling parameters and dehydration rates upper and lower kernels in maize

$\mathrm{A}$ ：下部籽粒脱水与灌浆参数相关分析; $\mathrm{B}$ : 上部籽粒脱水与灌浆参数相关分析; $G_{\text {mean }}$ : 平均灌浆速率, $D$ : 活跃灌期; TDR: 总脱水 速率; MCAPM: 生理成熟时籽粒含水率; ATFDTPM: 吐丝到生理成熟有效积温; $100 \mathrm{KW}$ : 百粒重。 “表示在 0.05 水平上差异显著; ${ }^{* *}$ 表示在 0.01 水平上差异显著。

A: correlation analysis between lower grain dehydration and grain filling parameters; B: correlation analysis between upper grain dehydration and grain filling parameters; $G_{\text {mean }}$ average filling rate; $D$ : grout duration; TDR: total dehydration rate; MCAPM: MC at physiological maturity; ATFDTPM: accumulated temperature from anthesis to physiological maturity; $100 \mathrm{KW}$ : 100 -kernel weight. ${ }^{*}$ and ${ }^{* *}$ indicate significant differences at $P<0.05$ and $P<0.01$, respectively.

\section{3 讨论}

合理的种植密度能够显著提高玉米产量 ${ }^{[23-24],}$ 不同熟期品种在密植条件下产量表现不同，在相同

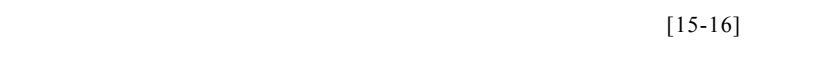
研究表明, 增加种植密度能够提高不同熟期玉米籽 粒产量, 在相同种植密度下先玉 335 具有更好的产 量优势, 2 年中先玉 335 的平均产量和最高产量较东 单 60 高 $8.9 \%\left(1303 \mathrm{~kg} \mathrm{hm}^{-2}\right)$ 和 $9.5 \%\left(3256 \mathrm{~kg} \mathrm{hm}^{-2}\right)$ 。 就产量构成而言，在保证单位面积穗数基础上，协 同提高穗粒数和百粒重扩大库容是实现玉米高产的 重要途径 ${ }^{[5]}$ 。本研究中, 种植密度每增加 10,000
株 $\mathrm{hm}^{-2}$, 先玉 335 和东单 60 的穗粒数分别减少 27 粒 和 28 粒, 百粒重分别降低 $0.9 \mathrm{~g}$ 和 $1.0 \mathrm{~g}$, 先玉 335 的平 均百粒重较东单 60 高 $4.8 \mathrm{~g}$, 穗粒数在品种间无显著 差异。因此, 高密下保持较高的粒重是先玉335较东 单60高产的主要原因。

籽粒灌浆速率和脱水速率直接影响玉米籽粒生 长发育过程中的含水量, 且籽粒灌浆速率的加快有 助于脱水速率的提高 ${ }^{[22,25]}$ 。籽粒灌浆和脱水特性在 不同熟期品种间的表现有较大差异, 晚熟品种灌浆 持续期比中熟和早熟品种长, 且自授粉到开始脱水 所需积温多、后期脱水慢、收获时籽粒含水率高 ${ }^{[26-27]}$ 。 
提高渐增期的灌浆速率和后期的脱水速率，可以缩 短渐增期库容建成时间, 相对延长快增期和缓增期 持续时间, 提高玉米籽粒产量和降低收获时籽粒含 水率 ${ }^{[13,16,28]}$ 。本研究中, 中熟品种先玉 335 不同粒位 籽粒灌浆启动早, 能较早达到最大灌浆速率, 灌浆 速率高，且后期籽粒脱水速率快，不同粒位的籽粒 含水率达到 $28 \%$ 和 $25 \%$ 所需积温较少, 较高的灌浆 速率和后期较快的脱水速率是先玉 335 获得较高粒 重和较低籽粒含水率的重要保障。不同脱水类型玉 米品种子粒含水率和灌浆均存在粒位效应, 与雌穗 中、下部籽粒相比，上部籽粒灌浆启动慢，最大灌浆 速率和平均灌浆速率低, 到达最大灌浆速率迟, 活 跃灌浆期较长, 籽粒粒重小 ${ }^{[4,6-7]}$, 本研究结果表明, 下部和上部籽粒粒重差异主要表现在灌浆 55 d左右, 与下部籽粒相比，上部籽粒活跃灌浆期和有效灌浆 期较长, 最大和平均灌浆速率较低, 达到最大灌浆 速率迟, 粒重小, 后期脱水快, 生理成熟时含水率 低, 含水率达到 $28 \%$ 和 $25 \%$ 所需积温少, 生产中可以 根据不同粒位的籽粒灌浆和含水率情况判断玉米的 成熟期和最佳收获期, 以提高籽粒产量和降低含水 率。相关性分析显示，下部和上部籽粒脱水速率与 灌浆速率的相关性不显著, 上部籽粒脱水速率与百 粒重呈显著负相关关系，上部籽粒粒重小可能是其 后期脱水快的原因。这一结果与前人在玉米低氮胁 迫下的研究结果相一致 ${ }^{[8]}$ 。最近研究得出种植密度 对籽粒脱水速率和收获时籽粒含水率的影响的结 论不一致, 有研究认为, 种植密度对玉米籽粒生理 成熟前的平均脱水速率和籽粒含水率无显著影响, 而对生理成熟后的籽粒含水率和脱水速率影响较 $大^{[13,17,29]}$; 也有研究认为, 随着种植密度的增加, 玉 米生理成熟期和收获期籽粒含水率增加, 而脱水速 率降低 ${ }^{[30]}$ 。原因可能与试验选用玉米品种的熟期有 关。本试验结果显示, 增加种植密度导致不同熟期 玉米不同粒位的籽粒灌浆速率降低和灌浆活跃期缩 短, 达到最大灌浆速率提前, 粒重降低, 后期脱水 加快，籽粒含水率达到 $28 \%$ 和 $25 \%$ 所需积温减少。与 东单 60 相比, 先玉 335 在高密条件下，不同粒位的籽 粒均能保持较高的粒重和较快的脱水速率, 有利于 群体库容量的提升和籽粒含水率的降低, 获得高产 和适宜机械粒收。提高种植密度能够加速籽粒后期 脱水, 可能是由于增密促进植株茎秆和叶片物质转 运，导致植株衰老，进而加快籽粒脱水 ${ }^{[12-13,17]}$ 。而关
于不同熟期玉米品种植株冠层结构和衰老对籽粒脱 水的影响生理机制还需更进一步深入研究。

\section{4 结论}

不同熟期玉米品种不同粒位的籽粒灌浆和脱水 特性对密度的响应存在较大差异, 适度增加密度不 仅提高不同熟期玉米籽粒产量，还加快其后期籽 粒脱水速率; 且 2 个品种籽粒灌浆和脱水特性对 增密的响应以上部籽更敏感。与晚熟品种东单 60 相 比，中熟品种先玉 335 适宜增密下不同粒位的籽粒 灌浆和脱水特性较为协调。因此, 选择中熟品种结 合增加密度能够实现陕北灌区玉米密植高产机械籽 粒直收生产。

\section{References}

[1] 李少昆, 赵久然, 董树亭, 赵明, 李潮海, 崔彦宏, 刘永红, 高 聚林, 薛吉全, 王立春, 王璞, 陆卫平, 王俊河, 杨祁峰, 王子 明. 中国玉米栽培研究进展与展望. 中国农业科学, 2017, 50: 1941-1959.

Li S K, Zhao J R, Dong S T, Zhao M, Li C H, Cui Y H, Liu Y H, Gao J L, Xue J Q, Wang L C, Wang P, Lu W P, Wang J H, Yang Q $\mathrm{F}$, Wang $\mathrm{Z} \mathrm{M}$. Advances and prospects of maize cultivation in China. Sci Agric Sin, 2017, 50: 1941-1959 (in Chinese with English abstract).

[2] Sango L, Gracietti M A, Rampazzo C, Bianchetti P. Response of Brazilian maize hybrids from different area to change in plant density. Field Crops Res, 2002, 79: 39-51.

[3] Tokatlidis I S, Koutroubas S D. A review of maize hybrids' dependence on high plant populations and its implications for crop yield stability. Field Crops Res, 2004, 88: 103-114.

[4] Shen L X, Huang Y K, Li T. Top-grain filling characteristics at an early stage of maize (Zea mays L.) with different nitrogen use efficiencies. J Integr Agric, 2017, 16: 626-639.

[5] 柏延文, 杨永红, 朱亚利, 李红杰, 薛吉全, 张仁和. 种植密 度对不同株型玉米冠层光能截获和产量的影响. 作物学报, 2019, 45: 1868-1879.

Bai Y W, Yang Y H, Zhu Y L, Li H J, Xue J Q, Zhang R H. Effect of planting density on light interception within canopy and grain yield of different plant types of maize. Acta Agron Sin, 2019, 45: 1868-1879 (in Chinese with English abstract).

[6] Wang J T, Kang S Z, Du T S, Tong L, Ding R S, Li S E. Estimating the upper and lower limits of kernel weight under different water regimes in hybrid maize seed production. Agric Water Manag, 2019, 213:128-134.

[7] 徐云姬, 顾道健, 张博博, 张耗, 王志琴, 杨建昌. 玉米果穗 不同部位籽粒激素含量及其与胚乳发育和籽粒灌浆的关系. 作物学报, 2013, 39: 1452-1461.

Xu Y J, Gu J D, Zhang B B, Zhang H, Wang Z Q, Yang J C. Hormone contents in kernels at different positions on an ear and their relationship with endosperm development and kernel filling in maize. Acta Agron Sin, 2013, 39: 1452-1461 (in Chinese with English abstract). 
[8] Wei S S, Wang X Y, Li G H, Qin Y Y, Jiang D, Dong S T. Plant density and nitrogen supply affect the grain-filling parameters of maize kernels located in different ear position. Front Plant Sci, 2019, 10: 180 .

[9] 张巽, 郝建平, 王璞, 张萍, 陈璐洁. 灌浆期低温对离体培养 玉米强弱势粒发育的影响。中国农业科学，2018，51: 2263-2273.

Zhang Y, Hao J P, Wang P, Zhang P, Chen L J. Effects of low temperature on maize superior and inferior kernels development during grain filling in vitro. Sci Agric Sin, 2018, 51: 2263-2273 (in Chinese with English abstract).

[10] 李少昆, 王克如, 谢瑞芝, 明博. 机械粒收推动玉米生产方 式转型. 中国农业科学, 2018, 51: 1842-1844.

Li S K, Wang K R, Xie R Z, Ming B. Grain mechanical harvesting technology promotes the transformation of maize production mode. Sci Agric Sin, 2018, 51: 1842-1844 (in Chinese with English abstract).

[11] 柴宗文, 王克如, 郭银巧, 谢瑞芝, 李璐璐, 明博, 侯鹏, 刘朝 巍, 初振东, 张万旭, 张国强, 刘广周, 李少昆. 玉米机械粒 收质量现状及其与含水率的关系. 中国农业科学, 2017, 50: 2036-2043.

Chai Z W, Wang K R, Guo Y Q, Xie R Z, Li L L, Ming B, Hou P, Liu C W, Chu Z D, Zhang W X, Zhang G Q, Liu G Z, Li S K. Current status of maize mechanical grain harvesting and its relationship with grain moisture content. Sci Agric Sin, 2017, 50: 2036-2043 (in Chinese with English abstract).

[12] 乔江方, 李川, 刘京宝, 朱卫红, 夏来坤, 谷利敏, 黄璐. 夏玉 米子粒含水率和子粒灌浆的粒位差异及其关系研究. 玉米科 学, 2016, 24(1): 56-62.

Qiao J F, Li C, Liu J B, Zhu W H, Xia L K, Gu L M, Huang L. Grain position effect of maize grain moisture content and grain filling and their relationship. J Maize Sci, 2016, 24(1): 56-62 (in Chinese with English abstract).

[13] 万泽花, 任佰朝, 赵斌, 刘鹏, 董树亭, 张吉旺. 不同熟期夏 玉米品种籽粒灌浆与脱水特性及其密度效应. 作物学报, 2018, 44: 1517-1526.

Wan Z H, Ren B Z, Zhao B, Liu P, Dong S T, Zhang J W. Grain filling and dehydration characteristics of summer maize hybrids differing in maturities and effect of plant density. Acta Agron Sin, 2018, 44: 1517-1526 (in Chinese with English abstract).

[14] 金益, 王振华, 张永林, 王殊华, 王云生. 玉米杂交种蜡熟后 籽粒自然脱水速率差异分析. 东北农业大学学报, 1997, 28(1): 29-32.

Jin Y, Wang Z H, Zhang Y L, Wang S H, Wang Y S. Difference analysis on the natural dry rate of kernel after wax ripening in maize hybrids. J Northeast Agric Univ, 1997, 28(1): 29-32 (in Chinese with English abstract).

[15] 钱春荣, 王荣焕, 赵久然, 于洋, 郝玉波, 徐田军, 姜宇博, 宫 秀杰, 李梁, 葛选良. 不同熟期玉米品种的籽粒灌浆特性及其 与温度关系研究. 中国农业科技导报, 2017, 19: 105-114.

Qian C R, Wang R H, Zhao J R, Yu Y, Hao Y B, Xu T J, Jiang Y B, Gong X J, Li L, Ge X L. Study on the grain filling characteristics and their relationship with temperature of maize hybrids differing in maturities. J Agric Sci Technol, 2017, 19(8): 105-114 (in Chinese with English abstract).

[16] 王晓慧, 张否, 刘双利, 曹玉军, 魏雯雯, 刘春光, 王永军,
边少锋, 王立春. 不同熟期春玉米品种的籽粒灌浆特性. 中国 农业科学, 2014, 47: 3557-3565.

Wang X H, Zhang L, Liu S L, Cao Y J, Wei W W, Liu C G, Wang Y J, Bian S F, Wang L C. Grain filling characteristics of maize hybrids differing in maturities. Sci Agric Sin, 2014, 47: 3557-3565 (in Chinese with English abstract).

[17] Wang X Y, Wang X L, Xu C C, Tian W M, Wang P, Meng Q F. Decreased kernel moisture in medium-maturing maize hybrids with high yield for mechanized grain harvest. Crop Sci, 2019, 59: 1-12.

[18] 张萍, 陈冠英, 耿鹏, 高雅, 郑雷, 张沙沙, 王璞. 籽粒灌浆期 高温对不同耐热型玉米品种强弱势粒发育的影响. 中国农业 科学, 2017, 50: 2061-2070.

Zhang P, Chen G Y, Geng P, Gao Y, Zheng L, Zhang S S, Wang P. Effects of high temperature during grain filling period on superior and inferior kernels' development of different heat sensitive maize hybrids. Sci Agric Sin, 2017, 50: 2061-2070 (in Chinese with English abstract).

[19] Yan P, Chen Y Q, Sui P, Vogel A, Zhang X P. Effect of maize plant morphology on the formation of apical kernels at different sowing dates and under different plant densities. Field Crops Res, 2018, 223: 83-92.

[20] 严定春, 朱艳, 曹卫星. 水稻栽培适宜品种选择的知识模型. 南京农业大学学报, 2004, 27(4): 20-25.

Yan D C, Zhu Y, Cao W X. A knowledge model for selection of suitable variety in rice production. J Nanjing Agric Univ, 2004, 27(4): 20-25 (in Chinese with English abstract).

[21] 陈传永, 王荣焕, 赵久然, 徐田军, 王元东, 刘秀芝, 刘春阁, 裴志超, 成广雷, 陈国平. 不同生育时期遮光对玉米籽粒灌浆 特性及产量的影响. 作物学报, 2014. 40: 1650-1657.

Chen C Y, Wang R H, Zhao J R, Xu T J, Wang Y L, Liu X Z, Liu C G, Pei Z C, Cheng G L, Chen G P. Effects of shading on grain-filling properties and yield of maize at different growth stages. Acta Agron Sin, 2014, 40: 1650-1657

[22] 李璐璐, 明博, 高尚, 谢瑞芝, 侯鹏, 王克如, 李少昆. 夏玉米 籽粒脱水特性及与灌浆特性的关系. 中国农业科学, 2018, 51: 1878-1889.

Li L L, Ming B, Gao S, Xie R Z, Hou P, Wang K R, Li S K. Study on grain dehydration characters of summer maize and its relationship with grain filling. Sci Agric Sin, 2018, 51: 1878-1889 (in Chinese with English abstract).

[23] Zhang M, Chen T, Latifmanesh H, Feng X M, Cao T H, Qian C R, Deng A X, Song Z W, Zhang W J. How plant density affects maize spike differentiation, kernel set, and grain yield formation in Northeast China? J Integr Agric, 2018, 17: 1745-1757.

[24] Gonzalez V H, Tollenaar M, Bowman A, Good B, Lee E A. Maize yield potential and density tolerance. Crop Sci, 2018, 58: 472-485.

[25] 张万旭, 明博, 王克如, 刘朝巍, 侯鹏, 陈江鲁, 张国强, 杨京 京, 车淑玲, 谢瑞芝, 李少昆. 基于品种熟期和籽粒脱水特性 的机收粒玉米适宜播期与收获期分析. 中国农业科学, 2018, 51: 1890-1898.

Zhang W X, Ming B, Wang K R, Liu C W, Hou P, Chen J L, Zhang G Q, Yang J J, Che S L, Xie R Z, Li S K. Analysis of sowing and harvesting allocation of maize based on cultivar maturity and grain dehydration characteristics. Sci Agric Sin, 
2018, 51: 1890-1898 (in Chinese with English abstract).

[26] 谢光辉, 杨建昌, 王志琴, 朱庆森. 水稻籽粒灌浆特性及其 与籽粒生理活性的关系. 作物学报, 2006, 27: 557-565.

Xie G H, Yang J C, Wang Z Q, Zhu Q S. Grain filling characteristics of rice and their relationships to physiological activities of grains. Acta Agron Sin, 2006, 27: 557-565 (in Chinese with English abstract).

[27] Brenda L G, Lucas B, María E O. Kernel water relations and duration of grain filling in maize temperate hybrids. Field Crops Res, 2006, 1: 1-9.

[28] Gasura E, Setimela P, Edema R, Gibson P T, Okori P, Tarekegne A. Exploiting grain-filling rate and effective grain-filling duration to improve grain yield of early-maturing maize. Crop
Sci, 2013, 53: 2295-2303.

[29] 方兴松. 种植密度对玉米籽粒灌浆及脱水特性的影响分析. 中国农业信息, 2014, (9): 51.

Fang X S. Effect of planting density on grain filling and dehydration characteristics of maize. Chin Agric Inf, 2014, (9): 51 (in Chinese).

[30] 王兵, 刘冬玲, 薛林, 张振良. 密度对玉米生理成熟后籽粒 含水率及脱水速率的影响. 安徽农业科学, 2018, 46(20): 38-40.

Wang B, Liu D L, Xue L, Zhang Z L. Effects of planting density on kernel moisture content and dehydration rate after maize physiological maturity. J Anhui Agric Sci, 2018, 46(20): 38-40 (in Chinese with English abstract). 